\title{
E-learning in higher education and social development
}

\author{
Gulzhaina Kassymova ${ }^{1,2^{*}}$, Rinad Kosherbayev $^{2}$, Mariyam Arpentieva ${ }^{3,4}$, Olzhas \\ Kenzhaliyev $^{5}$, and Aigerim Kosherbayeva ${ }^{2}$ \\ ${ }^{1}$ Yogyakarta State University, Yogyakarta, Indonesia \\ ${ }^{2}$ Abai Kazakh National Pedagogical University, Almaty, Kazakhstan \\ ${ }^{3}$ Sorbonne University College, University of Paris, Paris, France \\ ${ }^{4}$ M.V. Lomonosov Moscow State University, Moscow, Russia \\ ${ }^{5}$ Kazakh-British Technical University, Almaty, Kazakhstan
}

\begin{abstract}
The paper deals with digital education. Currently, digital education is getting popular, particularly in current pandemic event COVID 19 which has been emerged in China recently. Authors discussed online education issues. Authors reviewed different literature on e-learning and online education worldwide, as well as highlighted the online problems emerged in different countries. Now, when in many countries distance learning is actively imposed on people who do not have not only teaching aids and methodological competence for digital learning, when some people do not even have access to digital devices, there are no conditions for learning outside the classroom and there are many other problems, the problem digital inequality becomes its one channel for increasing general social inequality. Our research, which contributes to the study of current and likely future problems of digital education, its role and interaction with other spheres of society, including science and industry, is a contribution to solving the problem of social well-being, including sustainable development. Sustainable development is a controversial concept that combines two leading lines: the line of harmonization of the development of society in all its separate spheres and the harmonization of relations between spheres, and the line of achievements, evolution of each of the spheres and relations of spheres.
\end{abstract}

Keywords: education, digital, technology, develop.

\section{Introduction}

Digital learning as a component of education has a serious impact on the development of science and industry at the level of training and retraining of personnel in science and industry. New data concerning the development of research and improvement of work technologies in the world, are broadcasted to specialists and future specialists with greater speed and greater accessibility. This intensifies the processes of improving scientific research and stimulates industrial innovation. Science and industry, in turn, influence the

\footnotetext{
*Corresponding author: zhaina.kassym@gmail.com
} 
use, content and technology of digital education in a university. They develop and implement technological innovations, introduce new semantic guidelines, set new understandings of management tasks and technologies in all spheres of social life [1-5]. For example, B. Stigler, one is the leading philosopher of technology, developed an original interpretation of technology as a "technological community", different from any ethnopolitical (human) community. Technology and industry are not neutral. Modern digital technologies declare the functions of information reorganization, but they act as information management tools, including devaluation of information and devaluation of the process of cognition of information are destructive for mental and collective individualization. They lead to the "general proletarianization" of the social community. The problem of this society (community) is a lack of attention and desire (to know, create, love, live, etc.) [5-6]. As exemplified in robotic professor's H. Moravec, the plan" is to upload the human mind into a computer [7]: a digital, meliorated copy of the self, an 'upload' of personal identity, would enable a life without dying in a disembodied space of immortality [8]. The transhumanism [9] "wishes" to supplement and augment human cognition" and body [10]. The today's digital practices are closely connected to the idea of (self-)optimization of the human life, self-tracking and the algorithmisation of modern culture and life in general [11].

\section{Methods}

It is generally discussed about educational "brownfields" (old technologies) and "greenfields" (new technologies, including e-learning), building a foresight on the basis of repeatedly demonstrated their inferiority and limitations of functionalistic, inclusive, gaming, etc. models. As the main trends in e-learning, for example, one can single out the transition from MOOC (Massive open online courses) [12], which tried to imitate traditional learning in a digital environment, to microlearning (using short thematic videos), related podcasts, webinars (including the effect of the presence of a lecturer, to whom listeners can ask questions, providing feedback), gamification or learning through play (game forms of assimilation of information and practicing skills), training via phones / mobile learning and content curation - collection, systematization and re-publication of thematic information (repost and work with comments). We suppose that e-learning technology must combine both traditional and innovative methods. However, this line is very strong and some scientists recognize the digitalization of education as the "fifth leap" in the development of education in the world. The complete collapse of universities and other traditional schools, the creation of a unified information environment from which citizens can take what is necessary for successful consumption and trade, including selftrading (Commodification and desacralization of life activity), however, does not contribute to "leaps". E-education can become part of an effective and productive educational process in the context of:

- established relations with other traditional practices and models,

- established relations of the education system with industrial and business systems and government structures,

- $\quad$ subject to competent methodological support of the digital component of education per se.

We are talking specifically about the component of education, and not about digital education. No economy, as well as no education, can be "digital": digital technologies by themselves do not create anything without being connected with other technologies and reality in general [13].

Behind the seemingly quite obvious separation of the "old" (supposedly obsolete) and the "new" (supposedly successful) education often there is nothing real. Therefore, the true 
goal of many "education foresights" is either to fulfill the order for the momentary fixation of certain "fashion trends" of education, or to destroy and degrade education in the countries of the former "socialist camp".

\section{Results and discussion}

In Europe there is a project of the European School net (European School net), which unites more than 20 countries through an information portal, which contains materials created by teachers from different countries. In the UK, the Connected Educational Community project is being implemented, the e-Learning Toolkit was created for teachers using information technology in the classroom, giving students the opportunity to learn in a new way. The Tiger Leap Program that was launched in Estonia, was based on three main spheres: providing all schools with computers and the Internet, basic teacher training, as well as conducting e-courses in Estonian for general education institutions [14]. In the United States, the concept of e-learning includes a number of main national goals of educational technologies that provide access to IT in classrooms, schools, outside schools, aimed at using technology to achieve high results, including in the field of digital literacy, expanding research methods and understanding the world and general transformation of learning processes.

The e-Mexico program includes IT education for schoolchildren and adults, and includes the creation of local learning centers with open access to training courses and information. Edusat, RedEscolar ("School Network"), the National Educational Video Library and Enciclomedia work for the same purposes. The main goal of e-learning is the formation of the infocommunication identity of students, focused on "learning throughout life" on the basis of mobile infocommunication interaction in an open information and educational space. Moreover, one study about distance education quality from India argues that distance-learning degrees are not valid for central government jobs. Applicants send their degree certification verification to employers that they have attended traditional classes in order to get a government position [15]. However, recent study states distant education has become a stable form of implementing higher education. Advantages and disadvantages of this distant education form have been discussed since the form was introduced [16]. On the contrary, another study claims that teachers and learners were not ready to work in online mode since providing distance education requires special skills in both students and lecturers. This gap in the education system took place in the current even COVID 19 [17]. There should be a proper system for everyone to convey knowledge and to be acquired by students.

\section{Conclusion}

Orientation to the high achievements of each student, the high productivity of the work of each scientist, the high success of the work of each specialist for this should be combined with the development of a culture of human relations, an understanding of the value of a person and his life. Digital education is not a goal in itself, it is a means of achieving harmony in social relations, including the happiness of the people who make up this community. Now we see a hasty and largely one-sided study of the advantages and disadvantages of digital education, its different types and methods, but the moment will come when scientists and educators will begin to develop methods and technologies for digital learning in the context of the values of human life, human relations. Digital technologies are changing education - this is a reality that you need not run away from, but 
explore, helping them take their rightful place in teaching and educating people, their work in science and industry.

\section{References}

1. M.R. Arpentieva (Ed.), Psychology and pedagogy of the future: youth foresight. Youth and psychology: ideas and projects (Altaspera Publishing \& Literary Agency Inc., Toronto, 2018)

2. G.K. Kassymova, et al., Bulletin of National academy of sciences of the Republic of Kazakhstan, 6 (382), 195-207 (2019)

3. A. Kosherbayeva, A. Kulmeskhan, K. Gaziza, A. Asem, Procedia - Social and Behavioral Sciences, 89, 886-889 (2013)

4. A.D. Minghat, A.A. Suhaida Jamaludin, S.S. Mustakim, P.V. Shumov, Bulletin of the National Academy of Sciences of the Republic of Kazakhstan, 5(387), 233-240 (2020)

5. S. Lindberg, Educational Philosophy and Theory, 52(4), 384-396 (2020)

6. B. Stiegler, Automatic Society, Vol. 1, The Future of Work (Polity Press, Cambridge and Malden, 2016)

7. H. Moravec, Mind children. The future of robot and human intelligence (Harvard University Press, Cambridge, 1988)

8. C. Wiedemann, Transhumanismus. Bring mir den Kopf von Raymond Kurzweil! Frankfurter Allgemeine Zeitung (2015). Accessed on: December 16, 2020. [Online]. Available: https://www.faz.net/aktuell/feuilleton/transhumanismus-bring-mir-denkopf-von-raymond-kurzweil-13696362.html

9. J. Loh, Trans- und Posthumanismus (Zur Einführung) (Junius, Hamburg, 2018)

10. J. Danaher, The automotion loop and its negative consequences. Philosophical Disquisitions, April 27 (2015). Accessed on: December 16, 2020. [Online]. Available: http://philosophicaldisquisitions.blogspot.de/2015/04/the-automation-loop-and-itsnegative.html

11. L. Amoore, V. Piotukh, (eds.), Algorithmic life: Calculative devices in the age of big data (Routledge, London, 2016)

12. Y.H. Tsai, C.H. Lin, J.C. Hong, K.H. Tai, Computers \& Education, 121, 18-29 (2018)

13. D. V. Evzrezov, B. O. Mayer, Professional education in the modern world, 3(10), $17-$ 28 (2013)

14. A. Saurambayeva, Difficulties of Transition to Distance Learning: The Case of Kazakhstan. Central Asian Bureau for Analytical Reporting, August 26 (2020). Accessed on: December 16, 2020. [Online]. Available:

https://cabar.asia/en/difficulties-of-transition-to-distance-learning-the-case-ofkazakhstan\#

15. S. Kumar, The time of India. Distance learning degrees not valid for Central government jobs? (2008). Accessed on: December 16, 2020. [Online]. Available: http://timesofindia.indiatimes.com/articleshow $/ 3176365 . \mathrm{cms}$ ?from $=$ mdr\&utm_source $=$ contentofinterest\&utm_medium $=$ text\&utm_campaign $=$ cppst

16. I. Milevica, Materials of International Practical Internet Conference "Challenges of Science", 3, 131-136 (2020)

17. J. Arlinwibowo, H. Retnawati, B. Kartowagiran, G.K. Kassymova, Journal of Theoretical and Applied Information Technology, 98(14), 2828-2838 (2020) 